\title{
Astronomical pacing of late Palaeocene to early Eocene global warming events
}

\author{
Lucas J. Lourens ${ }^{1}$, Appy Sluijs ${ }^{2}$, Dick Kroon ${ }^{3}$, James C. Zachos ${ }^{4}$, Ellen Thomas ${ }^{5}$, Ursula Röhl ${ }^{6}$, Julie Bowles ${ }^{7}$ \\ \& Isabella Raffi ${ }^{8}$
}

\begin{abstract}
At the boundary between the Palaeocene and Eocene epochs, about 55 million years ago, the Earth experienced a strong global warming event, the Palaeocene-Eocene thermal maximum ${ }^{1-4}$. The leading hypothesis to explain the extreme greenhouse conditions prevalent during this period is the dissociation of 1,400 to 2,800 gigatonnes of methane from ocean clathrates ${ }^{5,6}$, resulting in a large negative carbon isotope excursion and severe carbonate dissolution in marine sediments. Possible triggering mechanisms for this event include crossing a threshold temperature as the Earth warmed gradually ${ }^{7}$, comet impact ${ }^{8}$, explosive volcanism ${ }^{9,10}$ or ocean current reorganization and erosion at continental slopes $^{11}$, whereas orbital forcing has been excluded ${ }^{12}$. Here we report a distinct carbonate-poor red clay layer in deep-sea cores from Walvis ridge $^{13}$, which we term the Elmo horizon. Using orbital tuning, we estimate deposition of the Elmo horizon at about 2 million years after the Palaeocene-Eocene thermal maximum. The Elmo horizon has similar geochemical and biotic characteristics as the Palaeocene-Eocene thermal maximum, but of smaller magnitude. It is coincident with carbon isotope depletion events in other ocean basins, suggesting that it represents a second global thermal maximum. We show that both events correspond to maxima in the $\sim 405-\mathrm{kyr}$ and $\sim 100$-kyr eccentricity cycles that post-date prolonged minima in the 2.25-Myr eccentricity cycle, implying that they are indeed astronomically paced.
\end{abstract}

Biotic phenomena similar to those characterizing the PalaeoceneEocene thermal maximum (PETM) have been locally recorded in the upper Palaeocene to lower Eocene, indicating the possibility of additional hyperthermal events, though of smaller magnitude ${ }^{14-16}$. Several short, negative carbon isotope shifts of up to $1 \%$ at deep-sea sites resemble the much larger-amplitude carbon isotope excursion at the PETM ${ }^{12}$. Orbital tuning suggested that these transients were controlled by maxima in the short-term eccentricity cycles, whereas the PETM carbon isotope excursion allegedly occurred near a minimum in the $\sim 405$-kyr eccentricity cycle, excluding orbital forcing as a triggering mechanism for the latter ${ }^{12}$.

One objective of Ocean Drilling Program (ODP) Leg 208 on the Walvis ridge (subtropical southeastern Atlantic Ocean) was to search for hyperthermal events within the lower Cenozoic greenhouse climate record. We recovered continuous, undisturbed lower Palaeogene successions at five sites along a 2-km water depth transect in multiple (mostly advanced piston core) holes. This resulted in the first complete early Palaeogene deep-sea record accumulated at relatively high sedimentation rates ${ }^{13}$. The uppermost Palaeocene and lower Eocene are composed of foraminifer-bearing nannofossil ooze, with a few chert layers and two deep-red clay layers marking the PETM and a younger distinctive horizon, named Elmo. Magnetobiostratigraphic results on Site 1262 (see Supplementary Information) reveal that the Elmo horizon at 117.1-117.2 m composite depth (m.c.d.) is slightly older than the chron C24r/C24n reversal boundary (115-116 m.c.d.) (Supplementary Fig. 1) and occurs within the lower part of NP11.

The Elmo horizon is $10-15 \mathrm{~cm}$ thick, and characterized by elevated magnetic susceptibility (MS) values at all sites (Fig. 1). Analysis of the $\mathrm{CaCO}_{3}$ content (expressed in weight per cent: wt $\%$ ) of the deepest Site 1262 (palaeodepth ${ }^{13}, 3,600 \mathrm{~m}$ ), intermediate Site 1266 (palaeodepth, 2,600 m) and shallowest Site 1263 (palaeodepth, 1,500 m) reveal that the increase in MS is linearly related to a drop in $\mathrm{CaCO}_{3}$ wt $\%$ (Supplementary Fig. 2). The $\mathrm{CaCO}_{3}$ wt $\%$ declines from $90-95$ below, to $\sim 40$ within, the red clay. High-resolution bulk carbon isotope records $\left(\delta^{13} \mathrm{C}_{\text {bulk }}\right)$ of Sites 1262, 1265, 1266 and 1267 reveal a negative excursion of $1.0-1.2 \%$ from below the first decline in $\mathrm{CaCO}_{3}$ wt $\%$ into the Elmo (Fig. 1). The $\delta^{13} \mathrm{C}_{\text {bulk }}$ of Site 1263 shows the largest depletion (1.4-1.6\%o), suggesting that the red clay layer at this site with the highest sedimentation rate ${ }^{13}$ is stratigraphically the most complete and/or least affected by the dissolution of primary calcite and the presence of reworked or secondary calcite. The post-Elmo interval mirrors the typical PETM signature with an exponential recovery to pre-excursion $\delta^{13} \mathrm{C}_{\text {bulk values. The bulk carbonate oxygen isotope record }}$ $\left(\delta^{18} \mathrm{O}_{\text {bulk }}\right)$ of Site 1263 shows a negative excursion of $\sim 1.6 \%$ (Fig. 2 ).

From Site 1263, we analysed the stable isotopic composition of individual specimens $(>300 \mu \mathrm{m}$ size fraction) of the surfacedwelling planktonic foraminifer Acarinina soldadoensis and the benthic foraminifers Cibicidoides spp. and Anomalinoides spp. (Fig. 2). The planktonic foraminiferal data show a much larger inter-specimen variability within each sample (especially within the Elmo horizon) than the benthic data. The (smoothed) carbon isotope record of $A$. soldadoensis $\left(\delta^{13} \mathrm{C}_{\text {A.soldadoensis }}\right)$ resembles the pattern of the bulk record, but shows a significantly larger negative excursion $(\sim 2.5 \%$ o $)$. The carbon isotope shift is much smaller in the benthic foraminiferal record than in A. soldadoensis, but the $(\sim 1 \%)$ trend through the carbonate-rich intervals equals that of the bulk and planktonic isotope records. Benthic foraminifera species richness is low and assemblages are dominated by diminutive Nuttallides truempyi and Abyssamina spp. species in the Elmo horizon. The

${ }^{1}$ Faculty of Geosciences, Department of Earth Sciences, and ${ }^{2}$ Laboratory of Palaeobotany and Palynology, Department of Palaeoecology, Utrecht University, Budapestlaan 4, 3584 CD Utrecht, The Netherlands. ${ }^{3}$ Faculty of Earth and Life Sciences, Vrije Universiteit, De Boelelaan 1085, 1081 HV Amsterdam, The Netherlands. ${ }^{4}$ Earth Science Department, University of California, Santa Cruz, Earth and Marine Sciences Building, Santa Cruz, California 95064, USA. ${ }^{5}$ Department of Earth and Environmental Sciences, Wesleyan University, 265 Church Street, Middletown, Connecticut 06459-0139, USA, and Center for the Study of Global Change, Department of Geology and Geophysics, Yale University, PO Box 208109, New Haven, Connecticut 06520-8109, USA. D. RG Research Center for Ocean Margins (RCOM), University of Bremen, Leobener Strasse, 28359 Bremen, Germany. ${ }^{7}$ Scripps Institution of Oceanography, University of California, San Diego, 9500 Gilman Drive, MC0208, La Jolla, California 92093, USA. ${ }^{8}$ Facoltà di Scienze, Dipartimento Scienze della Terra., Università "G. d'Annunzio" di Chieti, Campus Universitario Madonna delle Piane, Via dei Vestini 31, 66013 Chieti Scalo, Italy. 


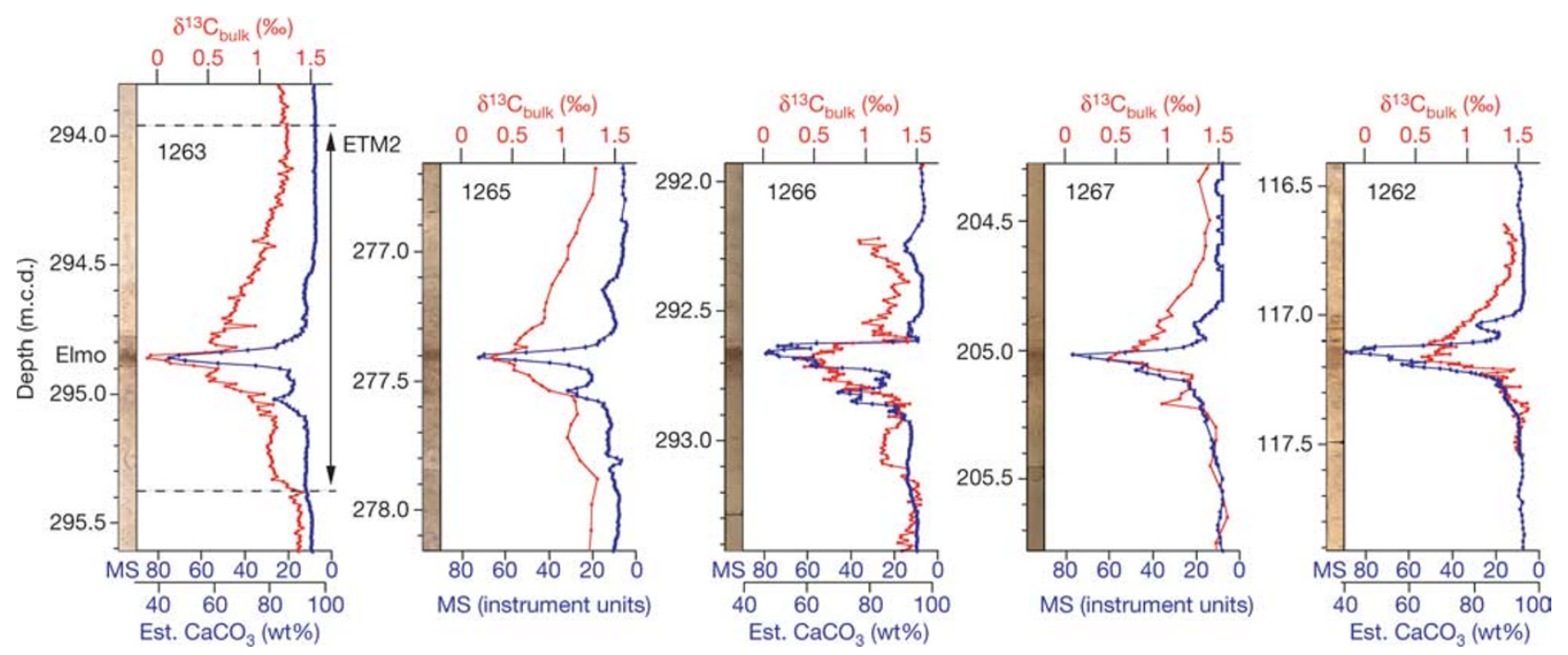

Figure 1 Bulk carbonate $\delta^{13} \mathrm{C}$ and magnetic susceptibility (MS) records across the Elmo horizon at five ODP Leg 208 sites. The $\mathrm{CaCO}_{3}$ wt $\%$ axes are estimates based on linear correlation with MS measurements on the same samples (Methods). Site numbers are given at the top left of each panel.
Site numbers and water depths (m) are as follows: $1263,2,717 \mathrm{~m} ; 1265$, $3,060 \mathrm{~m} ; 1266,3,798 \mathrm{~m} ; 1267,4,355 \mathrm{~m} ; 1262,4,755 \mathrm{~m}$. Digital images of the lithology are plotted at the left site of each panel. few measured benthic isotope values of the Elmo horizon, representing Anomalinoides spp. specimens (Cibicidoides spp. $>300 \mu \mathrm{m}$ are absent in the Elmo horizon), are similar to those from outside the clay layer, indicating that these are probably derived from bioturbated specimens. This suggests that large-sized benthic foraminifera were absent during deposition of the Elmo horizon, as commonly observed for the PETM ${ }^{17}$. The presence of light-coloured burrows within the red clay layer documents bioturbation, and could explain the scatter in the planktonic isotope values, and the less strong $\delta{ }^{13} \mathrm{C}_{\text {bulk }}$ excursion relative to $\delta{ }^{13} \mathrm{C}_{\text {A.soldadoensis. }}$. This possibility does not rule out that the magnitude of the excursion in the deep sea could have been damped owing to the larger carbon mass of this reservoir. The maximum oxygen isotope shift in $A$. soldadoensis $\left(\delta^{18} \mathrm{O}_{\text {A.soldadoensis }}\right)$ across the Elmo horizon is comparable to that of the $\delta^{18} \mathrm{O}_{\text {bulk }}$ record. There is only a $\sim 0.6 \%$ shift in the benthic oxygen isotope record, either because no in situ large benthic foraminifera are present in the Elmo horizon or changes in bottom water temperatures were minor.

To unravel the orbital relationship between the Elmo horizon and PETM, we studied the cyclic sedimentary patterns of the interlying interval in continuous spliced cores derived from advanced piston core holes only. Spectral analysis was applied on the colour reflectance $\left(L^{\star}\right)$ of Site 1267, and $L^{\star}$ and MS of Site 1262 (see Supplementary Information). The spectra of all records revealed the dominance of the long $(\sim 405-\mathrm{kyr})$ and short $(\sim 100$-kyr $)$ eccentricity cycles (Supplementary Fig. 3). Both components were extracted and could be unambiguously correlated between the records of these sites (Fig. 3). Four long-term maxima in MS (minima in $L^{*}$ ) occur between the Elmo horizon and PETM. The Elmo horizon corresponds to a fifth long-term MS maximum ( $L^{\star}$ minimum) and a

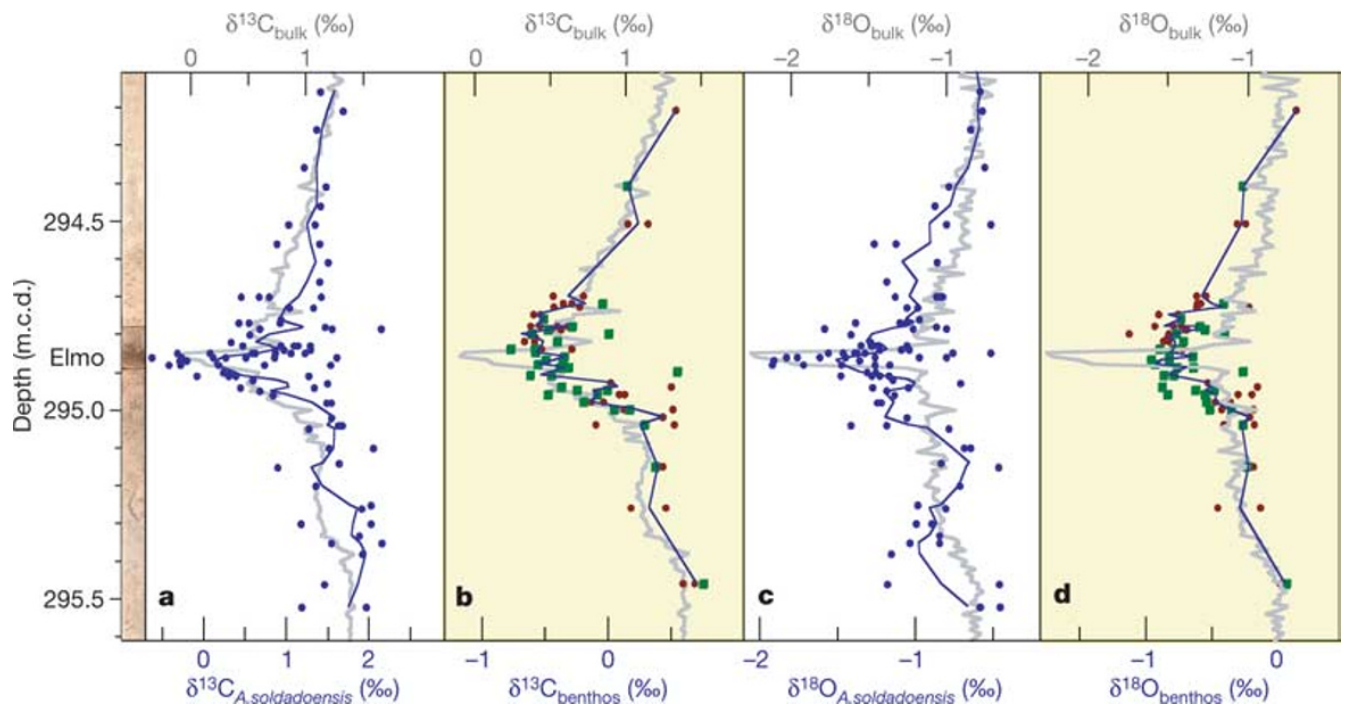

Figure 2 Stable isotope series of bulk sediment and single foraminifer specimens across the Elmo horizon at Site 1263. a, The $\delta^{13} \mathrm{C}$ values (blue dots) of the surface dwelling planktonic foraminifer $A$. soldadoensis $\left(\delta^{13} \mathrm{C}_{\text {A.soldadoensis }}\right)$. $\mathbf{b}$, The $\delta^{13} \mathrm{C}$ values of the bottom dwelling benthic foraminifers $\left(\delta^{13} C_{\text {benthos }}\right)$ Cibicidoides spp. (red squares) and Anomalinoides spp. (green dots). $\mathbf{c}$ and $\mathbf{d}$ as in $\mathbf{a}$ and $\mathbf{b}$ but for $\delta^{18} \mathrm{O}$. Grey lines in $\mathbf{a}$ and $\mathbf{b}$, and in $\mathbf{c}$ and $\mathbf{d}$, indicate respectively the $\delta^{13} \mathrm{C}$ and $\delta^{18} \mathrm{O}$ values of the bulk sediment $\left(\delta^{13} \mathrm{C}_{\text {bulk }}, \delta^{18} \mathrm{O}_{\text {bulk }}\right)$. Blue lines represent three-point moving averages on averaged values of duplicate analyses of a sample. 
short-term MS maximum ( $L^{\star}$ minimum) cycle. The red clay layer associated with the PETM ends in a long-term MS minimum ( $L^{*}$ maximum). If there were 11 climate precession cycles in the PETM interval ${ }^{18}$, then its carbon isotope excursion corresponds to a maximum (minimum) in the long-term MS $\left(L^{*}\right)$ cycle, similar to the Elmo.

A definite tuning of the early Eocene to astronomical computations is complicated, because the precision of the orbital solution more than $45 \mathrm{Myr}$ ago is limited ${ }^{19,20}$. Tuning is in principle possible for the 405-kyr eccentricity cycle, because of its longer duration of stability ${ }^{19,20}$ (Fig. 3). At 50 Myr ago, the absolute uncertainty in time is about $20 \mathrm{kyr}$ (ref. 20), but this did not lead to an astronomically tuned timescale owing to large uncertainties in radiometric age constraints for this time interval ${ }^{21}$. A second uncertainty derives from the chaotic behaviour of the inner planets related to the resonant argument $\theta=\left(s_{4}-s_{3}\right)-2\left(g_{4}-g_{3}\right)$, where $g_{3}, g_{4}$ are related to the precession of the perihelion and $s_{3}, s_{4}$ to the precession of the node of Earth and Mars ${ }^{20}$. This causes a large uncertainty in the determination of the time when the relatively stable $\sim 2.4-\mathrm{Myr}$ beat in eccentricity evolved from the $\sim 1.2-\mathrm{Myr}$ period when $\left(s_{4}-s_{3}\right)-\left(g_{4}-g_{3}\right)=0$ (that is, $\sim 2.25 \mathrm{Myr}$ in the nominal La2004 ${ }^{20}$ and $R 7^{19}$ solutions between $53-57 \mathrm{Myr}$ ago). This problem limits an accurate age determination of successive minima in this very long eccentricity cycle and the related intervals of reduced amplitude

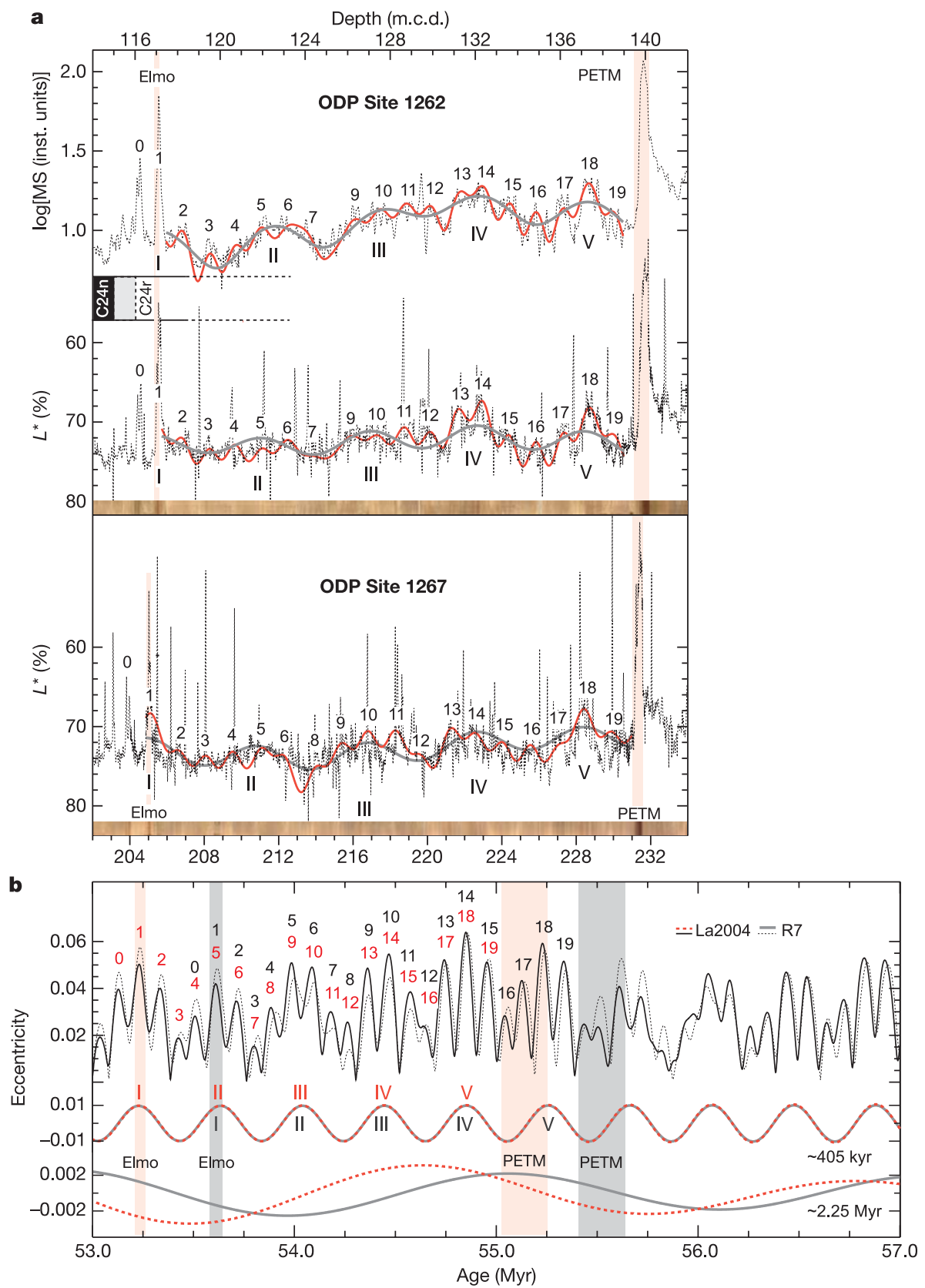

Figure 3 Astronomical tuning of the lower Eocene sediments at Walvis ridge to two different orbital computations. a, The extracted short (red lines) and long (grey lines) eccentricity-related cycles from magnetic susceptibility (MS) and colour reflectance $\left(L^{\star}\right)$ of sites 1262 and 1267 (dashed lines) represent respectively the $97.5 \%$ and $99.5 \%$ significant peaks in the CLEAN spectra (Supplementary Fig. 4). b, Correlation of the long- term (I-V) and short-term (0-19) eccentricity-related maxima to their correlative cycles in the $\mathrm{R}^{23}$ (grey) and La2004 ${ }^{24}$ (red) orbital solutions. The $405-\mathrm{kyr}$ and $\sim 2.25$-Myr cycles of eccentricity were extracted using a gaussian filter with a frequency of $0.00247 \pm 0.0001\left(\mathrm{kyr}^{-1}\right)$ and of $0.00043 \pm 0.0001\left(\mathrm{kyr}^{-1}\right)$, respectively. 
changes in the short eccentricity cycle, and explains the offset between the $\sim 2.25$-Myr cycles of the nominal La2004 and R7 solutions in the studied time interval (Fig. 3).

Because of these uncertainties, only a floating tuning could be realized (see also Supplementary Information). First, we emphasize that MS maxima ( $L^{*}$ minima) correlate to eccentricity maxima based on the distinct amplification of the precession-related lithological changes during the long- and short-term MS maxima (Supplementary Fig. 4). This observation is crucial, because it implies that the carbon isotope shifts associated with the PETM and Elmo horizon also correspond to maxima in the long and short eccentricity cycles (Fig. 3). Second, we correlated the (on average less amplified) $\sim 100$-kyr cycles within the second (II; Fig. 3) 405-kyr cycle to the minimum in the $\sim 2.25-\mathrm{Myr}$ cycle at $53.5 \mathrm{Myr}$ ago (La2004) or 54.0 Myr ago (R7) (Supplementary Fig. 5). Using this first order calibration, we tuned all long and short eccentricity cycles, implying that all cycles should be shifted one $\sim 405-\mathrm{kyr}$ cycle older in R7 than in the nominal La2004 solution (Fig. 3). As a result, the Elmo horizon correlates with the short eccentricity maximum at $\sim 53.235 \mathrm{Myr}$ ago (La2004) or $\sim 53.620 \mathrm{Myr}$ ago (R7), and the onset of the PETM carbon isotope excursion correlates with the long eccentricity maximum centred at $\sim 55.270 \mathrm{Myr}$ ago (La2004) or $\sim 55.675 \mathrm{Myr}$ ago (R7). This tuning implies that both events occurred briefly after a period of low-amplitude, short eccentricity changes associated with a minimum in the very long-term orbital perturbation of $\sim 2.25 \mathrm{Myr}$.

The $\delta^{13} \mathrm{C}_{\text {bulk }}$ negative shift of $1.4-1.6 \%$ in the Elmo horizon at Site 1263 is, with exception of the PETM carbon isotope excursion, of an unusually large magnitude for the early Palaeogene ${ }^{12}$. Its position just below $\mathrm{C} 24 \mathrm{n} / \mathrm{C} 24 \mathrm{r}$ and within NP11 suggests that this excursion correlates to the $\sim 1 \%$ depletion characterizing the $\mathrm{H} 1$ event in the North Atlantic (DSDP Site 550 and ODP Site 1051), the Southern Ocean (ODP Site 690) and the Pacific Ocean (DSDP Site 577) ${ }^{12}$ (see Supplementary Information). Moreover, the palaeosol carbonate isotope record from the Bighorn basin also shows a strong negative $\delta{ }^{13} \mathrm{C}$ excursion just below $\mathrm{C} 24 \mathrm{n} / \mathrm{C} 24 \mathrm{r}^{22}$, indicating that the carbon isotope excursion is global and recorded in both marine and terrestrial basins (Supplementary Fig. 6). The Elmo horizon, however, has yet not been recognized at other locations, although the $\mathrm{H} 1$ event is accompanied by high MS values at Sites 550 and $690^{12}$. Hence, the large drop in $\mathrm{CaCO}_{3}$ wt $\%$ in the Walvis ridge cores probably indicates a major global ocean lysocline shoaling, but in contrast to the $\mathrm{PETM}^{23}$, the calcite compensation depth appears to have remained below the palaeodepth of Site 1262. Application of the empirical temperature- $\delta^{18} \mathrm{O}$ relationship ${ }^{24,25}$ indicates furthermore that the $\sim 1 \%{ }^{18} \mathrm{O}_{\text {A.soldadoensis }}$ change within the Elmo horizon reflects a sea surface temperature rise of at least $3-4{ }^{\circ} \mathrm{C}$, about half of the mid- to high-latitude sea surface temperature changes estimated for the PETM ${ }^{26}$. All this suggests that the Elmo horizon characterizes a second pronounced early Eocene thermal maximum (ETM2; Fig. 1), similar to the PETM in both orbital and biogeochemical aspects, but of approximately half its amplitude in carbon isotope excursion, rise in sea surface temperature, and carbonate dissolution.

The linkage of both events to a similar orbital configuration disagrees with Cramer et al. ${ }^{12}$, who related the PETM to a minimum and H1 (ETM2 equivalent) to a maximum in a $\sim 405-\mathrm{kyr}$ cycle, thereby promoting the comet impact hypothesis ${ }^{8}$. In addition, according to their tuning the interval between the PETM carbon isotope excursion and $\mathrm{C} 24 \mathrm{n} / \mathrm{C} 24 \mathrm{r}$ should span $\sim 1.5 \mathrm{Myr}$, which is significantly shorter than the five $\sim 405$-kyr cycles $(\sim 2 \mathrm{Myr})$ that we found. These discrepancies can probably be attributed to large uncertainties in their approach of using low-amplitude bulk carbon isotope transient excursions and counts of poorly expressed lithological cycles from incomplete successions ${ }^{12}$. Hence, we suggest that the extreme seasonal contrast at both hemispheres during eccentricity maxima increased intermediate seawater temperatures, thereby triggering the release of oceanic methane hydrates. In this respect, the critical conjunction of short, long and very long eccentricity cycles and the long-term late Palaeocene to early Eocene warming trend may have favoured the build-up of a significant methane hydrate reservoir before its release during both events, thereby excluding unique mechanisms for explaining the PETM $^{5-11,27}$. The less extreme signal of ETM2 may reflect the inability of the methane hydrate reservoir to return to pre-PETM dimensions, especially under the warm conditions that prevailed in the interval spanning the two events ${ }^{1}$. Above ETM2 (H1) an increasing number of low-amplitude carbon transients occurred, of which the first, $\mathrm{H} 2^{12}$, seems to correspond with the two thin brown layers one 100-kyr cycle above the Elmo horizon (number 0 in Fig. 3), suggesting that the threshold for dissociation of clathrates was low during the early Eocene climatic optimum ${ }^{1}$, enabling even the short eccentricity cycles to trigger minor methane releases.

\section{METHODS}

Sampling and $\mathrm{CaCO}_{3} \mathrm{wt} \%$ analyses. Discrete sediment samples were collected at a $0.5-1-\mathrm{cm}$ spacing across the Elmo horizon in holes 1262A, 1263C and 1266C. All samples were freeze-dried and analysed for magnetic susceptibility per gram sediment ( $\mathrm{MS} \mathrm{g}^{-1}$ ) using an AGICO KLY-3 device. These records were compared to the split core point magnetic susceptibility (PMS) and whole core MS of the multiple sensor track (MS-MST) measurements obtained during Leg $208^{13}$. We converted all MS data to the MS-MST scale by performing linear regression analyses between $\mathrm{MS} \mathrm{g}^{-1}$ and PMS (Supplementary Fig. 2) and the conversion of PMS to MS-MST using the equation MST $=(\mathrm{PMS} \times 2.0683)+$ $7.8257\left(R^{2}=0.99\right)^{13}$.

Every fourth sample (but all within the Elmo horizon) was used for calcium carbonate analyses. The $\mathrm{CaCO}_{3}$ wt $\%$ was based on the amount of total carbon combusted with the Fison NA 1500 CNS analyser. Analytical precision and accuracy were determined by comparison with an international standard (BCR-71) and in-house standards (F-TURB, MM-91). The relative standard deviations, analytical precision and accuracy were better than 3\%. Several samples prepared for palynological studies revealed that no significant amount of organic carbon was present, with an uncertainty smaller than the analytical precision. A regression analysis between the $\mathrm{CaCO}_{3}$ wt $\%$ and the $\mathrm{MSg}^{-1}$ (converted to the MS-MST scale) was applied (Supplementary Fig. 2) to obtain the estimated $\mathrm{CaCO}_{3} \mathrm{wt} \%$ scale (Fig. 1).

Stable isotopes. Bulk stable isotope measurements were carried out for all sites with an average spacing of $4 \mathrm{~cm}$, but in $0.5-1-\mathrm{cm}$ resolution through the Elmo horizon. The isotope measurements were carried out using an ISOCARB common bath carbonate preparation device linked on-line to a VG SIRA24 mass spectrometer. Isotope values were calibrated to the PeeDee Belemnite (PDB) scale. Analytical precision was determined by replicate analyses and by comparison to international (IAEA-CO1 and NBS19) and in-house (NAXOS) carbonate standards, showing standard deviations of $<0.06 \%$ and $<0.1 \%$ or $\delta^{13} \mathrm{C}$ and $\delta^{18} \mathrm{O}$, respectively.

Stable isotope measurements of individual planktonic and benthic foraminiferal specimens were carried out using a CARBO-KIEL automated carbonate preparation device linked on-line to a Finnigan MAT252 mass spectrometer. Specimens were hand picked from the $>300 \mu \mathrm{m}$ fraction and cleaned in ethanol in an ultrasonic bath for $30 \mathrm{~s}$. Calibration to the international carbonate standard NBS19 revealed an analytical precision better than $0.03 \%$ and $0.05 \%$ o for $\delta^{13} \mathrm{C}$ and $\delta^{18} \mathrm{O}$, respectively.

\section{Received 17 November 2004; accepted 10 May 2005}

Published online 8 June 2005.

1. Zachos, J. C., Pagani, M., Sloan, L. C., Thomas, E. \& Billups, K. Trends, rhythms, and aberrations in global climate $65 \mathrm{Ma}$ to present. Science $292,686-693$ (2001).

2. Norris, R. D. \& Röhl, U. Carbon cycling and chronology of climate warming during the Palaeocene/Eocene transition. Nature 401, 775-778 (1999).

3. Kennett, J. P. \& Stott, L. D. Abrupt deep-sea warming, palaeoceanographic changes and benthic extinctions at the end of the Palaeocene. Nature 353, 225-229 (1991).

4. Koch, P. L., Zachos, J. C. \& Gingerich, P. D. Correlation between isotope records in marine and continental carbon reservoirs near the Palaeocene/ Eocene boundary. Nature 358, 319-322 (1992).

5. Dickens, G. R., O'Neil, J. R., Rea, D. K. \& Owen, R. M. Dissociation of oceanic methane hydrate as a cause of the carbon isotope excursion at the end of the Paleocene. Paleoceanography 10, 965-971 (1995).

6. Dickens, G. R., Castillo, M. M. \& Walker, J. C. G. A blast of gas in the latest 
Paleocene: Simulating first-order effects of massive dissociation of oceanic methane hydrate. Geology 25, 259-262 (1997).

7. Thomas, E. \& Shackleton, N. J. in Correlation of the Early Paleogene in Northwestern Europe (eds Knox, R. W. O. B., Corfield, R. M. \& Dunay, R. E.) 401-441 (Special Publication 101, Geological Society, London, 1996).

8. Kent, D. V. et al. A case for a comet impact trigger for the Paleocene/Eocene thermal maximum and carbon isotope excursion. Earth Planet. Sci. Lett. 211, 13-26 (2003).

9. Bralower, T. J. et al. High-resolution records of the late Paleocene thermal maximum and circum-Caribbean volcanism: Is there a causal link? Geology 25, 963-966 (1997)

10. Schmitz, B. et al. Basaltic explosive volcanism, but no comet impact, at the Paleocene-Eocene boundary: high-resolution chemical and isotopic records from Egypt, Spain and Denmark. Earth Planet. Sci. Lett. 225, 1-17 (2004).

11. Katz, M. E., Cramer, B. S., Mountain, G. S., Katz, S. \& Miller, K. G. Uncorking the bottle: What triggered the Paleocene/Eocene thermal maximum methane release? Paleoceanography 16, 1-14 (2001).

12. Cramer, B. S., Wright, J. D., Kent, D. V. \& Aubry, M.-P. Orbital climate forcing of $\delta^{13} \mathrm{C}$ excursions in the late Paleocene-early Eocene (chrons C24n-C25n). Paleoceanography 18, doi:10.1029/2003PA000909 (2003).

13. Zachos, J. C., et al. in Early Cenozoic Extreme Climates: The Walvis Ridge Transect (eds Zachos, J. C., Kroon, D. \& Blum, P.) (Ocean Drilling Program, College Station, Texas, 2004).

14. Thomas, E. \& Zachos, J. C. Was the late Paleocene thermal maximum a unique event? Geol. För. Stockh. Förh. [Trans. Geol. Soc. Stockholm] 122, 169-170 (2000).

15. Bujak, J. P. \& Brinkhuis, H. in Late Paleocene - Early Eocene Biotic and Climatic Events in the Marine and Terrestrial Records (eds Aubry, M.-P., Lucas, S. G. \& Berggren, W. A.) 277-295 (Columbia Univ. Press, New York, 1998).

16. Röhl, U., Norris, R. D. \& Ogg, J. G. in Causes and Consequences of Globally Warm Climates in the Early Paleogene (eds Wing, S. L., Gingerich, P. D., Schmitz, B. \& Thomas, E.) 567-589 (Special Paper 369, Geological Society of America, Boulder, Colorado, 2003).

17. Thomas, E., Zachos, J. C. \& Bralower, T. J. in Warm Climates in Earth History (eds Huber, B. T., MacLeod, K. \& Wing, S. L.) 132-160 (Cambridge Univ. Press, Cambridge, 2000)

18. Röhl, U., Bralower, T. J., Norris, G. \& Wefer, G. New chronology for the late Paleocene thermal maximum and its environmental implications. Geology 28, 927-930 (2000).
19. Varadi, F., Bunnegar, B. \& Ghil, M. Successive refinements in long-term integrations of planetary orbits. Astrophys. J. 592, 620-630 (2003).

20. Laskar, J. et al. A long term numerical solution for the insolation quantities of Earth. Astron. Astrophys. 428, 261-285 (2004).

21. Machlus, M., Hemming, S. R., Olsen, P. E. \& Christie-Blick, N. Eocene calibration of geomagnetic polarity time scale reevaluated: Evidence from the Green River Formation of Wyoming. Geology 32, 137-140 (2004).

22. Koch, P. L. et al. in Causes and Consequences of Globally Warm Climates in the Early Paleogene (eds Wing, S. L., Gingerich, P. D., Schmitz, B. \& Thomas, E.) 49-64 (Special Paper 369, Geological Society of America, Boulder, Colorado, 2003).

23. Zachos, J. C. et al. Rapid acidification of the ocean during the PaleoceneEocene Thermal Maximum. Science (in the press).

24. O'Neil, J. R., Clayton, R. N. \& Mayeda, T. K. Oxygen isotope fractionation in divalent metal carbonates. J. Chem. Phys. 51, 5547-5558 (1969).

25. Shackleton, N. J. Oxygen isotope analyses and Pleistocene temperatures reassessed. Nature 215, 15-17 (1967).

26. Zachos, J. C. et al. A transient rise in tropical sea surface temperature during the Paleocene-Eocene thermal maximum. Science 302, 1151-1154 (2003).

27. Svensen, $\mathrm{H}$. et al. Release of methane from a volcanic basin as a mechanism for initial Eocene global warming. Nature 429, 542-545 (2004).

Supplementary Information is linked to the online version of the paper at www.nature.com/nature.

Acknowledgements This research used samples and data provided by the Ocean Drilling Program (ODP). This work was supported by the Netherlands Organisation for Scientific Research (L.J.L., A.S. and D.K.), Utrecht Biogeology Centre (A.S.), Deutsche Forschungsgemeinschaft (U.R.), and the National Science Foundation (J.C.Z., E.T. and J.B.). We thank the scientific and nonscientific crew of ODP Leg 208, J. Suhonen in particular, and G. Ittman, A. E. van Dijk, G. M. Ganssen, S. J. A. Jung, H. B. Vonhof, P. L. Koch, H. Brinkhuis, F. J. Hilgen, T. Kouwenhoven and J. W. Zachariasse for technical support, advice and comments

Author Information Reprints and permissions information is available at npg.nature.com/reprintsandpermissions. The authors declare no competing financial interests. Correspondence and requests for materials should be addressed to L.J.L. (llourens@geo.uu.nl). 